\title{
VIA CRUCIS SERTANEJA: REPRESENTAÇÕES DOS CORPOS FEMININOS EM SEARA VERMELHA
}

\author{
Thaílla da Silva Sena ${ }^{1}$; Valter Guimarães Soares ${ }^{2}$ \\ 1. Bolsista PEVIC/UEFS, Graduando em Licenciatura em História, Universidade Estadual de Feira de Santana, e- \\ mail: thaillassena@gmail.com \\ 2. Orientador, Departamento de Educação, Universidade Estadual de Feira de Santana, e-mail: \\ vgsoares@hotmail.com
}

PALAVRAS-CHAVE: literatura; sertão; feminino, Jorge Amado.

\section{INTRODUÇÃOO}

A partir dos anos de 1930 o sertão emerge como tema e problema, tanto no campo da ciência, da poesia, como também em romances brasileiros. Dentre este conjunto de romances destaca-se Seara Vermelha, do escritor Jorge Amado, publicada no ano de 1946. A narrativa toma como cenário o sertão, a saga dos beatos, cangaceiros, retirantes expulsos das terras do latifúndio em direção a São Paulo. O livro traz uma novidade geográfica, posto que encena outra cartografia da Bahia na obra amadiana, na medida em que ali não recria a vida baiana nas ruas, becos e ladeiras de Salvador ou das cidades do Recôncavo, nem é ambientado em terras grapiúnas ou nas matas do cacau.

O romance é dividido em quatro partes. O prólogo, intitulado "A Seara", em que Amado nos apresenta o tema central de seu livro: o latifúndio, e também os personagens e conflitos que serão desenvolvidos ao longo do romance, em particular, a família de Jucundina e Jerônimo, que é expulsa da terra e peregrina pelos Caminhos da Fome, livro primeiro, subdividido em A caatinga; $O$ rio e $O$ trem de ferro, onde dramatiza a diáspora de massas populacionais sertanejas em direção às terras paulistas.

Caminhos que desembocam nas "Estradas da esperança", livro segundo, encabeçado pelos três filhos do casal, que fugiram de casa antes do êxodo: José (que se junta ao bando de Lucas Arvoredo), Jão (que se torna soldado da polícia militar e é designado para combater beato Estevão e seus seguidores), e Juvêncio, ou Nenén (que entra no exército como soldado, engaja-se na vida política, vira comunista e participa da Intentona de 1935). São, portanto, partes que se ocupam do cangaço, do messianismo e dos embates políticos do Partido Comunista e da Aliança Nacional Libertadora. O livro se encerra com A colheita, que, como indicia a metáfora, se volta para a reorganização do Partido Comunista.

Nos trabalhos sobre Seara Vermelha é recorrente a abordagem sobre a intenção política do romance. No plano de trabalho que vem sendo desenvolvido colocamos em questão não apenas a intenção política do romance, mas propomos, sobretudo, investigar a representação amadiana de sertão e do sertanejo, inventariando as circunstâncias históricas que condicionam a narrativa. É, pois, sobre a representação dos sujeitos sertanejos que pretendemos colocar em questão neste trabalho. Mais especificamente, investigar a representação dos corpos femininos, suas afetividades e desejos no romance Seara Vermelha, indagando como, no obra, representações sobre a paisagem-sertão constroem visões sobre os corpos femininos lidos enquanto sertanejos.

A importância do recorte de gênero no trabalho se dá, especialmente, por questionar a ideia de um "sujeito humano universal", e o androcentrismo na ciência. A proposta se 
justifica pela quase inexistência de trabalhos sobre a temática proposta e diferenciar-se da maioria das análises sobre a obra de Jorge Amado, que priorizam os romances ambientados na cidade da Bahia ou a saga do cacau. Nesse sentido, o trabalho pode contribuir para a ampliação do conhecimento científico acerca da construção das representações sobre o corpo na obra amadiana, como também, para colocar em discussão o papel das narrativas literárias na elaboração de imagens e estereótipos sobre o corpo da mulher sertaneja.

\section{MATERIAL E MÉTODOS OU METODOLOGIA (ou equivalente)}

O material tomado para realização da pesquisa é o próprio romance Seara Vermelha. Nesse sentido, o romance será tratado, a um só tempo, como fonte e objeto de análise. Ao tomar o discurso literário como material de análise recorro à noção de representação como elemento conceitual que permite articular o entrecruzamento entre o literário e o histórico (PESAVENTO, 1998: 19). Na trilha aberta pelas novas abordagens dos estudos da cultura, considero literatura e história como representações, como versões da realidade, formas de re-criação da realidade, construtoras de sentido e sistemas de significação. Mesmo compreendendo as diferenças que guardam entre si, suas especificidades a partir de diferentes métodos e procedimentos.

Para CHARTIER (2002), as representações expressam relações de força em uma dada estrutura social, remetendo para os diferentes modos como os sujeitos sociais percebem a si mesmos, a sua época e o mundo em que vivem, construindo a partir dessas percepções sistemas de identidade, de crença e de conhecimento. As representações do mundo social variam sócio-historicamente, sendo, por tanto, imprescindível a articulação entre texto-contexto, de modo a compreender como a época escreve e se inscreve na narrativa. Nesse sentido, estudo os processos pelo quais se constrói um sentido para o corpo da mulher sertaneja, buscando compreender como, nos discursos analisados, a figura da mulher sertaneja é construída, pensada, dada a ler (CHARTIER, 2002: 17).

O corpo ocupa uma posição estratégica na constituição do feminino. Tanto o sexo quanto a idade são noções que remetem a naturalização do corpo, e uma forma de combater essa naturalização é perguntar-se pelos mecanismos sociais que levam a interpretação desses fatores como dados naturais (ALVES, 2004: 357).

De forma abreviada e provisória, o percurso metodológico previsto constitui-se basicamente de a) levantamento e leitura de bibliografia: 1) teórica, com vistas a melhor explicitação do referencial teórico da pesquisa; 2) sobre Jorge Amado, destacando sua posição como militante comunista: memórias, biografias; 3) análises e interpretações do romance; b) revisar a literatura que tematiza o sertão d) análise textual da obra tomada como objeto de pesquisa.

\section{RESULTADOS E/OU DISCUSSÃO (ou Análise e discussão dos resultados)}

Jorge Amado toma o sertão e o sertanejo como alegoria para denunciar e interpretar a exploração, as misérias e injustiças da realidade brasileira e do sertão-nordestino em particular. Mas ao fazê-lo, reelabora um repertório do já-dito-sertão, a partir dos signos da seca, suas mazelas e seus tipo sociais (cangaceiros, retirantes, beatos, camponeses), colocando-os a partir de outra perspectiva - revolucionária. Paisagem ambientada sob o 
signo do agreste e do inóspito, lugar do seco, do espinho, do veneno, dos animais primitivos e rastejantes; do flagelo e do flagelado; de vidas secas e gordos latifúndios. Imagens que se configuraram como paisagem sertaneja. Paisagem que se tornará cristalizada e fixada como regra de ver e dizer esta região sob a pena de não legitimidade, do não reconhecimento (Albuquerque Jr., 2008:210-12).

A elaboração da paisagem-sertão e dos sujeitos que a compõem é feita de modo imbricado. Seco é o ambiente, secas são as pessoas. Corpos magros, de poucas palavras e quase inexistentes gestos de afetos. São traços que compõem alguns dos tipos sociais no romance - retirantes, cangaceiros. Com exceção do beato, cujo instrumento de luta é a fala denunciatória dos fins dos tempos. Alguns elementos são constitutivos desses personagens, a força, a resistência. Os camponeses que peregrinam pelos caminhos da fome são elevados à condição de heróis ao desbravarem esses caminhos: "Marta e Vicente, os outros todos também, vindos de onde não havia água, onde a terra era seca e agreste, onde só os animas mais bravos resistiam, e o homem, que era mais bravio de todos" (AMADO, 1986:119).

Os corpos femininos do romance serão construídos a partir desses mesmos elementos, entretanto, restrito ao ambiente familiar e privado. Ao elaborar imagens e personagens míticas do sertão, tais como os cangaceiros, beatos e retirantes, Jorge Amado se apropria de formulações de que seria o sertanejo (masculino), personagem cristalizado enquanto viril, forte e resistente, para compor este lugar-sertão. Num movimento dialético, o autor também (re)elabora formulações sobre o outro desta faceta, o feminino sertanejo.

As formulações amadianas sobre o feminino sertanejo oscilam entre as imagens mulher forte/mulher-macho; moça ingênua e altruísta, mulheres de famíla, como também figuras femininas astutas. Duas personagens são centrais para a composição do feminino no romance, a saber, Jucundina, matrona da família de retirantes, e Marta, sua filha. A partir deste momento nos deteremos em uma leitura sobre algumas figuras femininas e masculinas do romance. Em primeiro lugar, Jucundina que é a matriarca da família. Ela é a personagem que não está tecendo o enredo político-econômico do romance na dicotomia entre os que oprimem ou daqueles que reagem à opressão (beatos e cangaceiros). Ela sofre as consequiências dessas tomadas políticas, tal como peregrinar até São Paulo por razão da expulsão.

Ela é apresentada como alicerce da família, ela quem nutre a esperança de reencontrar os filhos que migram antes da expulsão. Ela também se alia a um estereótipos de sertanejo viril, forte e bravio. Ela que vai resguardar a comida que a família tem e negar se juntar a outra família que peregrina há mais tempo que eles, o que significa dizer que estão em uma situação mais escassa em relação aos alimentos. Jucundina procura tardar a fome para os seus, imagem que se liga a figura da fera materna que protege suas crias. Em segundo lugar, sua filha Marta, que durante todo trajeto da família se mostra solícita em ajudar qualquer dos parentes a superar os infortúnios. Marta chega mesmo a renuncia seu sonho de se encontrar com Vicente em São Paulo -moço pelo qual se apaixona enquanto admira o rio e suas embarcações na cidade de Juazeiro- em prol da família. Marta acaba por se deixar desvirginar pelo médico da cidade de Pirapora, responsável por emitir o laudo médico que autoriza o consentimento da passagem de trem de Pirapora a São Paulo, custeada pelo estado paulista, sacrifício este realizado na 
intenção de que seu pai consiga o laudo falsificado, uma vez que se encontra tuberculoso. O resultado é a expulsão de Marta da família pelo pai, convertendo-se em prostituta para que o pai possa seguir viagem até São Paulo.

Os signos que rondam Marta são aqueles da inocência, altruísmo e resignação a seu destino de sofrimento, quase como uma santa, mesmo que uma santa-prostituta. No entanto, o preço que a personagem Marta paga é o que uma morte simbólica na narrativa, sua presença corporal não mais retorna. Apenas em recordações da infância por seu sobrinho Tonho e pelos delírios de seu pai Juvêncio no leito de morte.

Ambas, Jucundina e Marta figuram- se em personagens fundamentais para que o enredo do romance gire, elas fazem parte da construção do sentido político do romance. Entretanto, nos deteremos em analisar a representação dos corpos dessas duas personagens.

Uma imagem pode ser elencada como constitutiva dos corpos dessas personagens: uma árvore. Uma árvore robusta que seca com o tempo. Jucundina e Marta, mãe e filha, são apresentadas no romance como personagens que compartilham corpos similares distantes pelo tempo. Marta que é objeto de desejo de personagens masculinos por onde passa. A sertaneja jovem se aproxima de uma árvore frondosa, desejável. A descrição do corpo de Marta destaca os contornos, as curvas, mesmo magras e mau-alimentada. Marta é, de certa forma, uma árvore robusta, e desejável.

Jucundina tem seu corpo descrito como magro, mais próximo do signo da seca. Já se encontra ressequida, não é objeto de desejo, mas de respeito. É a base familiar. Um corpo seco, castigado pelo sol, pelo sofrimento. Uma árvore seca, mas de raízes profundas, é a base da família.

\section{CONSIDERAÇÕES FINAIS (ou Conclusão)}

A partir da análise documental percebemos que a composição das personagens do romance é feita a partir dos signos que compõem a paisagem: o agreste, a seca, o inóspito. Para sobreviver neste ambiente, os sujeitos precisam ser resistentes, bravios, viris, atributos lidos enquanto masculinos. As personagens femininas são encenadas mais pelo signo da resistência do que da masculinidade/virilidade. A representação dos corpos femininos sertanejos-amadianos é atravessada pela temporalidade: possivelmente frondosas e desejáveis enquanto jovens, entretanto, são corpos que vão secando ao sol causticante e as agruras da vida.

\section{REFERÊNCIAS}

ALBUQUERQUE JR., Durval M. Nos destinos de fronteira: história, espaços e identidades regionais. Recife, Bagaço, 2008.

ALVES, Andréa M. "Algumas reflexões sobre sexo, idade e cor". In: CadernoCRH. Salvador, v.17, n.42, Set/Dez. 2004. Pp. 357-364.

AMADO, Jorge. Seara Vermelha, romance; ilustrações de Carlo Scliar. $45^{\text {a }}$ Ed. Rio de Janeiro, Record, 1986.

CHARTIER, Roger. História cultural: entre práticas e representações. Lisboa: Difel, 2002.

PESAVENTO, Sandra Jatahy. Contribuição da história e da literatura para a construção do cidadão: a abordagem da identidade nacional. In: LEENHARDT, Jacques; 
PESAVENTO, Sandra Jatahy (Org.). Discurso histórico e narrativa literária. Campinas: EDUNICAMP, 1998, p. 17-40. 